Özet:

2050'li yıllarda 85 yaşın üzerindeki insanların nüfusunun bugünden yedi kat fazla olacağı beklenilmektedir. Bu nedenle, kentler büyük bir titizlikle düzenlenmelidir. Yaşlılar, toplumdan kaçma, fiziksel karşılaştırmalar gibi birçok değişik sorunları yaşamaktadır. Kentsel alanlar yaşlıların gidebilece ği önemli yerler haline gelmekt; , erişim, mesafe kriterleri yaşlı insanların hareketliliğini belirlemede ön plana çıkmaktadır. Kamusal alandaki mikro ortam tasarımı önemli bir kriter haline gelirken, tasarımların gelişmeye açık bir şekilde, fiziksel, entelektüel güçlerin de ğişimi dikkate alınarak, yaşlanmaya bağlı olarak değişkenler ve bu insanların çevresine uyumu göz önünde tutularak yapılması gerekmektedir. Yaşllları kentsel koşullar içinde tutmak için farklı disiplinler ve ölçeklerde çalışmalar yapılmaktadır. Bu çalışmalar bütünleştirilemediği için henüz kentsel alanda yaşlılarla ilgili sorunlar çözülememiştir. Yaşlıların kentsel alandaki sorunları, yapılacak düzenlemelerin, üst ölçekli politikalardan başlayarak lokal ölçeklere indirilmesi, özerk çözümler yerine disiplinlerarası uygun çözümlerin bulunmasıyla sağlanacaktır.

Summary:

In 2050's, the population of people above the age of 85 years will be seven times more than today. The city should be arranged with great care and sensitivity. The elderly confront various problems like escaping from the society, physical comparisons. The urban areas in cities become important place to visit for the elderly. The criteria of access, distance, come to the fore in determining their activity. Also micro environment designs in the public environment became an important criteria. Designs area required to be made in a way open to improvement, by looking at the changing dynamics of physical and intellectual powers, in consideration of variables dependant on aging and harmony of these people with their environment. Many studies from different disciplines have been produced to keep the elderly population in the city centres. However due to the lack of entegration among these studies and researches, the problems elderly people faced in the cities have remained unsolved. These problems can be solved only with the formation of necessary policies which should be produced in every scale from national governments to local goverments. It also requires an interdiscplines'approach to tackle these problems.

Anahtar kelimeler:

Yaşlılık, insan ilişkileri, erişebilirlik,

kamusal alan, donatı

Keywords:

Elderly, human relations, access, public area, equipment

\title{
Yaşlıların Kentsel Mekanda Kendilerini Daha Iyi Ifade Edebilmeleri İçin Alınması Gereken önlemler
}

Yrd. Doç. Dr. Pelin Gökgür MSGSÜ Mimarlık Fakültesi, Şehir ve Bölge Planlama Bölümü

\section{Giriş}

İnsanlık tarihinde ilk kez bugün 400 milyon olan 65 ve 84 yaşları arasındaki nüfusun 2050'li yıllarda 1.3 milyara kadar artış göstereceği, 85 yaşın üzerindeki nüfusun ise bugünden 7 kat daha fazla olacağ 1 yapılan istatistikler sonucu ortaya konulmaktadır (Thierry Paquot 2000,76). Bu bağlamda yaşlılığın neyi ifade ettiği, kentle olan ilişkilerinin nasıl düzenlenmesi gerektiği ve kentsel mekanda yaşlı insanların yeri ne olmalı gibi konuların giderek çok daha büyük bir titizlikle ele alınması gerekmektedir.

Yaşlılık, bir yaşam sürecinin ürünü ve aynı zamanda özel yaşamın, sosyal ve mesleki yaşamın, insan ilişkilerinin,

duygusal ilişkilerin bir sonucu olarak ortaya çıkmaktadır. Yaşlılık dönemi bir "gevşeme, kendini serbest bırakma dönemi” olarak tanımlanabilir. Bu dönem yaşam biçiminde ve aktivitelerde yeni düzenlemeleri ve hazırlıkları gerektirir. Yaşlılıktan dolayı ortaya çıkan fiziksel değişimler, hem yaşlıların hem de bulundukları çevre için olumsuz bir kimlik sergiliyebilmektedir. Bu da yaşlıların; çevreyle olan ilişkilerini kısıtlamaları, çevrelerini daraltmaları, geri çekilerek kendilerini bulundukları ortama hapsetme gibi sonuçlar doğurabilmektedir. Hatta yaşlı insanlar, kamusal alanlarda, gençlerin arasında önüne geçilme hissi, "herhangi birşey yapabilme gücünü kaybetmiş" ve "yavaşlama" "ihtiyacı duyan insanlar haline gelmektedir (Clément vd., 1996, 93).

Yaşlılar onları iten bir kalabalıktan korunmak için sakinliği, bulundukları kenti terkederek daha küçük yerlerde yaşamayı, konutlarından gerekmedikçe çıkmamayı, huzurevlerini, hayvanlarla ve bitkilerle olmayı tercih edebilmektedir. Toplumdan kaçma, fiziksel karşılaştırmalar (gençlikyaşlılık), güvensizlik gibi birçok değişik sorun yaşarken, özellikle kendilerini tanımayan insanlar arasında olmak onları rahatsız etmekte ve endişelendirmektedir. Kentte kalmayı tercih eden yaşlılar giderek kendi mekanlarına kapanmakta, dışarı çıktığında da ancak "yönlendirilmiş ve kısa" mesafeleri, ikinci derece yolları, sakin parkları tercih etmek zorunda kalmaktadırlar. 
Yaşlıların hareketsizliği bir yandan

fiziksel güçlerinin azalmasından kaynaklanırken, bunun yanısıra "emniyet, emniyetsizlik, bir yere ulaşmak için gereken tempoya sahip olamama, fiziksel değişikliklerden dolayı yaşanan zorluklar" gibi daha birçok faktör onların hareketlerindeki yavaşlamaya neden olmaktadır (Clément vd., 1996: 93). Yaşlilarda fiziksel güçlüklerin dışında anılan sebeplerin pek çoğu kentsel düzenleme politikalarıyla çözülebilecek sorunlardır. Bu düzenlemeler kamusal alanda olabileceği gibi yarı kamusal ve özel alanlarda da göz önünde bulundurulmalıdır. Bu çalışmada yaşlıların kentsel alanda karşılaştığı güçlükler ele alınarak onların toplum içinde var olmalarını sağlayacak, farklı ölçeklerde ve farklı disiplinlerin ürettiği çözümler irdelenmeye çalışılacaktır.

\section{Kentsel Alanda Karşılaşılan Güçlükler}

Yaşlı insanların otonomisi gerek ekonomik gerek psikolojik açıdan önem kazanırken, kendi kendine yetebilme, özgür olabilme duyguları sosyal ve fiziksel çevreleriyle ilintilidir.

Yapılan birçok araştırmada yaşılıların yalnızca kazanılmış alışkanlıklarını korumaktan, günlük rutin işlerinden başka yeni mekanlar bulmak, yeni yerler keşfetmek gibi isteklerinin yanısıra, sık sık da küçük ve sakin yerlerden çok canlı, yaşayan yerleri tercih ettikleri belirlenmiştir.

Gezinti yaşlılar için en önemli aktiviteler arasında yer alırken, yaşa bağlı olarak gezinti veya yürüyüş aktiviteleri yakın çevre, semt gibi sınırlanmış mekanlarda gerçekleşmeye başlamaktadır. Yaşlı kişiler giderek bütün ihtiyaçlarını yakın çevrelerinde görmeye başlarken, bulundukları yakın çevre onlar için sığınılan sabit bir noktaya dönüşerek, kendi dar çevrelerine hapsedilmiş olmaktadırlar. Oysa bunun tam aksine kent merkezine doğru hareket etmede devamlılığın sağlanması, yaşlıların gerçekleştirdiği aktivitelerde özgürlük ve özgüven verirken aynı zamanda onları teşvik etmek, gayrete getirmek, merak uyandırmak açısından da önemli olmaktadır.

Yaşlılar için özellikle kentte yer alan kamusal alanlar önemli ziyaret yerleri haline gelmekte ama bu alanlara gitme sıklıkları veya gitmeme durumu "erişim kolaylığına" veya "yakınlık" kriterlerine bağlı olarak değişim göstermektedir. Erişim, mesafe, uzaklık, yakınlık kriterleri yaşlı insanların hareketliliğini belirlemede ön plana çıkarken mesafelerin yakınlığı bu insanların yardımlaşması ve moral açısından önem kazanmaktadır. Sonuç olarak yaşlı insanların yaşadıkları fiziksel, psikolojik ve zihinsel sorunlara fiziksel mekanda yaşadıkları sorunlar eklenmektedir. Yaşlıları yavaşlatan veya hızlandıran bu sorunlar özellikle büyük kentlerde daha çok artış göstermektedir.

Bunlar sırasıyla; yaya geçitleri, konforsuz kaldırımlar, gürültü, kirlilik, trafik ışıkları, sosyal güvensizlik, çok süratli otomobil kullanma, trafik kargaşası, devamlılığ olmayan yaya yolları, giderek uzaklaşan alışveriş merkezleri, kaldırımlar üzerinde gelişigüzel yer alan kent mobilyaları, otobüs durakları, kamu taşımacılı $\breve{g}$, kamusal aydınlatma, kamusal alanlara erişim ve buna benzer sorunlar olabilmektedir.

Yaşlıların kentsel alanda karşılaştı $\breve{g}_{1}$ bu sorunlar mimari projeler, özel tasarımlar, gerontolojik politikalar ve yasalarla giderilmeye çalışılmaktadır. 


\section{Yaşlılı Üzerine Farklı Disiplinler ve} Farklı Ölçeklerde Yapılan Çalışmalar

Birçok ülkede, yaşlılarla ilgili sorunları azaltmak veya ortadan kaldırmak için özellikle gerontolojiye bağlı olarak birtakım noktasal uygulamalar gerçekleşti-rilmektedir. Bunun sonucunda kent-yaşlılık ilişkilerindeki sorunların kentsel ve sosyal çözümlemelerden çok mediko-sosyal ağırlıklı olduğu görülmektedir.

Gerontoloji yaşlılığa dinamik bir perspektiften bakmayarak, kent-yaşlılık ilişkilerinin bir "yardım" düşüncesiyle ele alınması yolunda çalışmalarını yoğunlaştırmıştır. Bu çalışmalar kentsel alanda, yaşlıların kamusal alana kolay ulaşımı için sağlanan özel ulaşım hizmetleri, telefonlu alarm sistemleri, bankalarda özel güvenlik şeklinde noktasal olarak geliştirilmiştir (La Ville des Vieux 1998, 46). Yaşl11ık için ortaya konan politikalar sektörel mantıkla işlemeye başlamıştır.

Gerontolojik politikalar dışında, birçok ülkede düzenlenen yasalarla yaşlılara kentsel alanda kolaylıklar getirilmeye çalışılmıştır. Bunlara örnek olarak 13 Aralık 2000 tarihinde Fransa'da çıkartılan "Dayanışma ve Kentsel Yenileme Yasası"nda, "kamusal alanların düzenlenmesi engelli insanların bu alanlara erişimini sağlayacak şekilde olmalıdır" maddesi yer almaktadır. Bu madde engelli insanlarla birlikte, yaşlılar ve çocuklar gözönüne alınarak düzenlenmiştir. Bu düzenlemeler 2 ana başlık altında toplanmaktadır: 1-Erişim ve yol kalitesi için dikkate alınmasl gereken noktalar;

-Bir noktadan bir noktaya erişim

-Yön ve röper noktaları bulma -Kentsel hizmetlere erişim
-İletişim, katılım

-Emniyette olmak

2-Kentsel düzenlemelerde dikkate alınması gereken noktalar;

-Zemin sularının tahliyesi

-Aydinlatma

-Kentsel mobilyalar

-Duraklar

-Emniyet

-Trotuvarlar

-Taşıt yollarından geçiş konularıyla detaylandırılmıştır (Tétard J.P. 2002, 77-78).

Bir başka ilginç örnek Danimarka'da yaşlılar için yapılan çalışmalardır. Burada 1992'den beri yaşlılık sorunları yalnızca devlet ve yerel yönetimler tarafından ele alınmış, böylece sektörler arası yaşanan karmaşa ortadan kaldırılmıştır. Bu konuda yapılan çalışma ve araştırmalarıyla Danimarka, Avrupa'da iyi bir örnek oluşturmaktadır. Yerel yönetimler, bu konuda profesyonelleri ve gönüllü kuruluşları biraraya getirerek, eylem bütünlüğünün düzenlenmesinde tek otorite durumundadır (www.amba.france.dk/fr).

Avrupa Birliği çerçevesinde, 1982 yılında Viyana'da yapılan “1. Dünya Yaşlılar Toplantısı”, ikinci kez 2002 yılında Madrid'de gerçekleşmiş, 160 ülkenin katıldığ $\breve{b}_{1}$ bu son toplantıda uluslararası bir eylem planı oluşturulmuş ve bu eylem planının 3 ana başlığı şu şekilde belirlenmiştir:

-Yaşlılar ve gelişim

-Sağlıkla ilgili konuların iyileştirilmesi ve yaşlılara uygun çevrelerin yaratılması -Her yaştan insanı içine alacak toplumların oluşturulması (http:/srv-tt.tt.mtas.es/frances). $\mathrm{Bu}$ toplantıdan çıarılan en önemli sonuç; yaşlılık olgusunun dünya çapında tartışmaya açılması ve uzun yaşama faktörünün sosyal ve ekonomik gelişme politikalarının içine dahil edilmesidir. 
Türkiye'de de 2003 yılında Başbakanlık Özürlüler İdaresi tarafından hazırlanmış "Engelliler Yasa Taslağı" bulunmaktadır.

Bu taslak kısaca şu başlıkları

kapsamaktadır:

-Engellilere maddi destek,

-Engellilere evinde hizmet,

-Engellilerin ev tadilatının devlet

tarafından üstlenilmesi,

-Özürlülere iş imkanı,

-Özürlülere üniversite kontenjanı

ayrilmas1,

-Hakların takibi için kurul oluşturulması (www.ntvmsnbc.com/news).

$\mathrm{Bu}$ yasa tasarısında ağırlıklı olarak maddi destek ve hizmet anlayışının ön plana çıktığı, yaşlılıların yaşadıkları ortamla bütünleşmesini sağlayacak önlemlerin söz konusu olmadığı görülmektedir.

Bunların yanısıra bazı ülkelerde yıllardan beri gerçekleştirilen mimari projeler vardır. 1960'lı yıllarda Hollandalı mimar Herman Hertzberger tarafindan gerçekleştirilen projede kamusal alan, sokak, meydan gibi öğelerin etrafında kentsel mikro ortam oluşturmak için yeni formlardan yararlanılmıştır. Buradaki amaç, kentsel ortamı projelere dahil etmektir. Yine 1980'li y1llarda mimar Michel Velly tarafından gerçekleştirilen projede yaşlıların konutları üstü kapalı bir sokak etrafında toplanırken, farklı mimarlar toplu yaşamı kamusal meydana açılan, üstü kapalı bir meydan etrafında toplamışlardır. Bu projelerde "kentin, yaşlıların terapisinde bir model oluşturması" fikrinden yola çıkılarak, "kent ve kentsel mekanlar" bir örgütlenme modeli olarak kullanılmıştır (Dehan 1999:75). Terapi eğilimi kentsel canlılığa ve kentsel hareketlilik potansiyeline bağlanmaktadır. Hedef, yaşlıları yaşadıkları yerlerde tutabilmek için gereken önlemlerin alınmasıdır. Yaşlılara yönelik kentsel alanda mikro ortam tasarımıyla ilgili önlemler ise kısaca şu şekilde belirlenmiştir:

Yaya Geçitleri: Yaya geçitlerinde rampalar oluşturmak, geniş caddelerde geçişi kolaylaştırmak için refüjlerin yapılması, yayalara öncelik tanınması, sürat ve 1şıklandırma konularında trafik ölçülerinin ayarlanması, otomobil trafiğinin yaşlıları dikkate alarak düzenlenmesi, karşıdan karşıya geçen yaşlıları kanalize edip emniyetlerini sağlamak için bariyer veya sınırlandırıcıların konulması, Duraklar: Durakların korunaklı ve iyi aydınlatılmış olması, oturma ve dayanma elemanları ile donatılması, yerel iklimin getirdiği zorluklar ve olanaklar düşünülerek tasarlanması, toplu taşımaya yönelik otobüs durakları arasındaki mesafelerin hareket zorluğu olan yaşlılara göre ayarlanması,

Aydınlatma: Vandalizm, hırsızlık ve şiddet olaylarına karşı iyi bir aydınlatmayla mekanları daha görünür kılmak, elektrik direklerinin kolay ve rahat görülmesi için yeterli genişlikte olmasını sağlamak, Erişim-Yol Kalitesi-Emniyet: Parklar ve meydanların eve mesafesinin 500 metrenin altında olması, bu alanlara erişimde, otobüs duraklarında, cadde ve sokaklarda dinlenme, dayanma, yaslanma için destek, dayanak noktaları oluşturmak, Kaldırımlarda parmaklık, alçak duvarlar, çiçeklikler ile spontane bir dinlenme sağlamak (la Ville des Vieux 1998: 426). Yaya ulaşımında sürekliliğin sağlanması için kent mobilyalarının yer seçiminde kriterlerin belirlenmesi, Trafik 1şıkları, levhalar, ulaşımla ilgili göstergelerin yaşlıların görme koşullarına göre tasarlanması, yazı boyutlarının ve aydınlatma esaslarının dikkate alınması, belirgin ve anlaşılır hale getirilmesi, Düşmeye neden olacak kaygan

74 Sayı 4, Mayıs 2006 
malzemeler ve yürümeyi engelleyecek pürtüklü malzemelerin yer döşemesi olarak kullanılmaması,

Toplu taşım araçlarıyla kent merkezine kolay erişimin sağlanması; yaşlılar tarafından "karşılaşma" ve "gezi" alanı olarak görülen kamusal alanlara ve kentsel hizmetlere erişebilirlik mesafelerinin belirlenmesi,

Yaya yollarının üzerine park eden taşıtların engellenmesi, kaldırımlarda gereken konforun sağlanması, Kentsel mobilyalar: Bulunduğu mekanda iyi konumlanmış olması, açık alanlarda doğal 1şık, gölge-1şık öğelerini gözönüne alarak yerleştirilmesi, toplanma, sohbet etme fırsatlarını vermesi, yaşlıların fiziksel koşulları gözönüne alınarak tasarlanması, Kamusal alan: Kamusal alanların sadeleştirilmesi, kalitesinin arttırılması, yürüme kolaylığı, kolay erişilebilen kamusal alanların oluşturulması, bu alanlarda yaşlıların sosyalleşmesini sağlayabilecek düzenlemelerin yapılması, yön ve röper noktalarının oluşturulması... gibi daha birçok önlemlerin alınması gerekliliği ortaya konulmaktadır.

CERTU (Centre d'études sur les réseaux, les transports, l'urbanisme) tarafından 2000 yılında Fransa'da engelliler için yayınlanan “ Karayolla Erişim Genelgesinde" ise normlar şu şekilde ortaya konulmuştur;

Yaya ulaşımı için kaldırımdaki normlar;

-Genişlik: Minimum1.80 m.
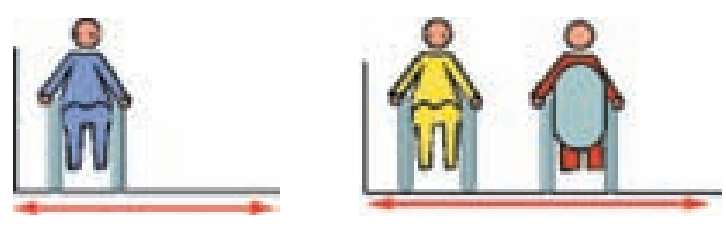

$1,80 \mathrm{~m}$ minimum $1,80 \mathrm{~m}$ minimum
-Eğim: Maksimum \% 5, her 10 metrede bir dinlenme sahanlıkları, topoğrafyanın uygun olmadığ 1 alanlarda ise maksimum $\% 12$ eğim,

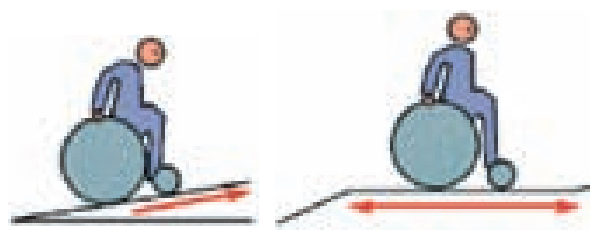

$\% 5$ maksimum

-Enine eğimler: Maksimum \% 2 eğim,

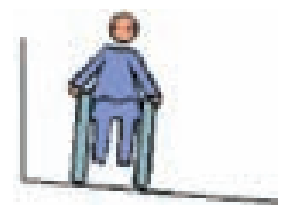

$\% 2$ maksimum

-Yer Döşemeleri: Kaygan ve tekerleklerin dönmesini engelleyecek şekilde pürüzlü olmaması, yerdeki aralık, yarık ve deliklerin $2 \mathrm{~cm}$.'den az olması, tehlikeli çukurlardan korunma, görsel yetersizliklerin ortadan kaldırılması için renk ve malzeme farklılı̆̆ının getirilmesi,

Trotuvarlar: Yaya geçitlerinde trotuvar bordürlerinin kaldırılması ve cadde seviyesine getirilmesi, maksimum genişliğin $1.20 \mathrm{~m}$. olması, bu alanlarda görme engellileri uyarmak için yer döşemesinde farklılık yaratılması, uyarı sinyalleri oluşturulması, Merdivenler: Merdiven genişiliği $1.20 \mathrm{~m}$, merdivenin bir tarafında duvar varsa 1.30 m., merdiven iki duvar arasında ise 1.40 m., basamak yüksekliği maksimum 16 $\mathrm{cm}$., genişliği ise minimum $28 \mathrm{~cm}$., merdiven korkulukları 0.90 / 1.00 metre olmas1, 3 basamaktan 
fazla olan merdivenlerde korkuluk konulmasi,

Trafik Işıkları: Engellilerin, özellikle görme engellilerin yaya geçitlerinden geçiş süresinin ayarlanması için yürürlükte olan normların sağlanması,

Direkler: Çevreyle tezat oluşturacak renklerin seçimi, direklerin maksimum $0.40 \mathrm{~cm}$. yükseklikte bariyerlerle çevrilmesi,

Park Etme Alanları: Arabanın sol tarafından tehlike oluşturmadan inebilmek için boylamasına alanların oluşturulması, düzenli sinyalizasyon sistemi kurulması, park ettikten sonra trotuvara erişim için minimum 0.80 metre genişlikte yerlerin ayrilması,

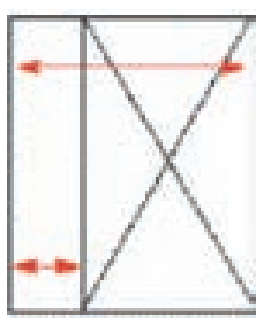

3.30 metre minimum

0.80 metre

Olağanüstü hallerde çağrı hizmeti:

Yeni karayolu ulaşımında, tünellerde ve otoyollarda zorunlu çağrı noktalarının oluşturulması,

Duraklar: Kollektif ulaşım araçlarını kullanabilmek için durak yerlerine kolaylıkla erişimin sağlanması yolunda tedbirler alınmasıdır (www.route.equipment.gouv.fr).

$\mathrm{Bu}$ durum genelgenin, engellilerle birlikte yaşlıları da kapsadığını, belirlenen normların her iki grup için geçerli olabileceğini göstermektedir.

Sonuç olarak; yasalar, mimarî projeler, mikro ortam tasarımları, gerontolojik vb. çalışmalar; kentsel alanda yaşlıların yaşadığ 1 sorunların çözümlenmesini hedefleyen makro ve mikro ölçekli çalışmaları kapsayarak, farklı disiplinler, farklı bakış açıları ve farklı ölçeklerde ele alındığını göstermektedir. Bu düzenlemelerin genellikle birbirinden bağımsız olarak yapılması sorunların çözülmesini zorlaştırmakta ve yaşlılık sorununu özerkleştirerek, kent / yaşlılık ilişkilerini zorlaştırmaktadır.

\section{Sonuç}

Kentsel alanda yaşanan hızlı dönüşümler; kamusal alan ve özel alanların içiçe geçmesi, kentsel mekanda farklılaşan konutlar, kent merkezinin fonksiyonlarını kaybetmesi, otomobil sahiplerinin kamusal alanın bir bölümünü sahiplenmesi, kısaca globalleşmeyle birlikte ortaya çıkan yeni yaşam biçimleri, yaşlılar için sosyalleşmenin en önemli yerleri olan kentsel alanların kalitesini düşürerek bu alanların karmaşık hale gelmesine neden olmuştur. Bu sorunlar her yaştan nüfus grubunu ilgilendirmekte ama özellikle yaşlılar ve engelliler için çok daha yıldırıcı olmaktadır.

Yaşlılar için yapılan bu çalışmaların sonucunda da yaşlılarla ilgili birçok sorunun giderilemediği görülmüştür. Alınan önlemlere rağmen, kentsel mekanda yaşanan sorunların devam etmesinin en önemli nedeni kent ve yaşlılık ilişkisinin noktasal ilişkilerin içinde ele alınmasından kaynaklanmaktadır. Çoğunlukla "gerontolojik politikalarla" ele alınan yaşlılık problemi, kentteki özel aktörleri harekete geçirerek sektörel politikalar şeklinde gerçekleşmiştir.

Oysa yaşl1lık-kent ilişkileri, kentsel düzenleme politikalarından bağımsız özerk bir şekilde ele alındıklarında, hedeflenen amacı tam olarak gerçekleştirememektedirler. 
Kent düzenleme ve yaşlılık-kent ilişkileri; kent içindeki çeşitli grupların sosyal rolleri ve yerleri ele alınarak, mekansal fonksiyonlarla bütünleştirilerek tasarlanmalıdır. Yaşlılık-kent ilişkileri, kentlerde yaşanan diğer sorunlarla birlikte ele alınarak, kentsel düzenleme politikalarının dinamik yapısı içinde çözümlenmelidir. Kentsel ve sosyal politikalar içinde ele alınacak yaşlılık dönemi, her ölçekte yapılacak düzenlemelerin daha etkin kılınmasını sağlayacaktır.

Şehircilik çerçevesinde ele alınması gereken konular:

Lokal ölçekte özellikle kamusal alanların, yolların yayalar düşünülerek tasarlanması, yol hiyerarşisi, kamusal taşımacılık, mekansal fonksiyonlar, kentsel şebeke ve hizmetlerin devamlılığı-erişilebilirliği gibi konular olmalıdır. Üst ölçeklerde ise ekonomik ve politik aktörlerin getireceği çözümler; özel hizmetler şeklinde gelişen önlemler yerine, tüm kentsel sorunlarda olması gerektiğ gibi kamusal hizmetlerle çözülmesini sağlamak, sektörel mantıkla bu sorunun özerkleşmesini engelleyecek mekansal ve sosyal politikaları belirlemektir. Bu doğrultuda, 2002 yılında Madrid'de yapılan toplantıda, yaşlılılık olgusunun uluslararası platformda ele alınarak, sosyal ve ekonomik gelişme politikaları içinde düşünülmesi olumlu bir gelişme olarak kabul edilebilir.

Simone de Beauvoir'ın ifade ettiği gibi "toplum genç kalmış, sağlıklı, rahat ve seyahat edebilen, kendine ait meşguliyetleri olan sorunsuz yaşlıları kucaklarken, yorgun, hasta, terkedilmiş, güçten düşmüş, başkalarına bağımlı yaşlıları dikkate almayarak kendi köşelerinde sonlarını beklemeye terkedebiliyor". Bu durumu ortadan kaldırmak için yaşlılara yönelik yasal düzenlemeler ve tasarımların varlığı olumlu bir gelişme olarak kabul edilse bile, kent/yaşlılık ilişkileri yönetiminin üst ölçekli kentsel ve sosyal politikalar içinde ele alınmadan, başarılı olamayacağı görülmektedir 1

\section{KAYNAKÇA}

S.Clément, J.Mantovoni, M.Membrado. 1996. "La Ville A la Vieillesse se ménager et se risquer" Les Annales de la Recherche Urbaine, Say1 73

P.Dehan. 1999. "La ville du troisième Age" Urbanisme, Say1 305

J.Sanchez. 1992-1993. "Accessibilités, mobilités et handi caps" Les Annales de la Recherche Urbaine, Say1 58

Yerpez, Joel .der. 1998. La Ville des Vieux-Recherche sur une citè a humaniser, Editions de L'Aube.

Tétard Jean Pierre 2002. La Nécessaire Reconquete du Projet Urbain, L'Harmattan

Paquot T. 2000. "Le Dernier Age" Urbanisme, Say1 311

www.route.equipement.gouv.fr

www.amba.france.dk/fr

www.ntvmsnbc.com

http://srv-tt.tt.mtas.es/frances 